\title{
Efficacy of presepsin for identification of patients with microbiologically documented sepsis
}

\section{Authors: Dunja Mihajlovic ${ }^{1,2}$, Arsen Uvelin ${ }^{1,2}$, Vesna Pajtic ${ }^{1,2}$, Vladimir Vrsajkov ${ }^{2}$, Dunja Uveric ${ }^{2}$ Faculty of Medicine, University of Novi Sad ${ }^{1}$; Emergency center, Clinical center of Vojvodina ${ }^{2}$}

\begin{abstract}
Concentration of presepsin in patients with suspected sepsis
\end{abstract}

3500
3000
2500
2000
1500
1000
500

0

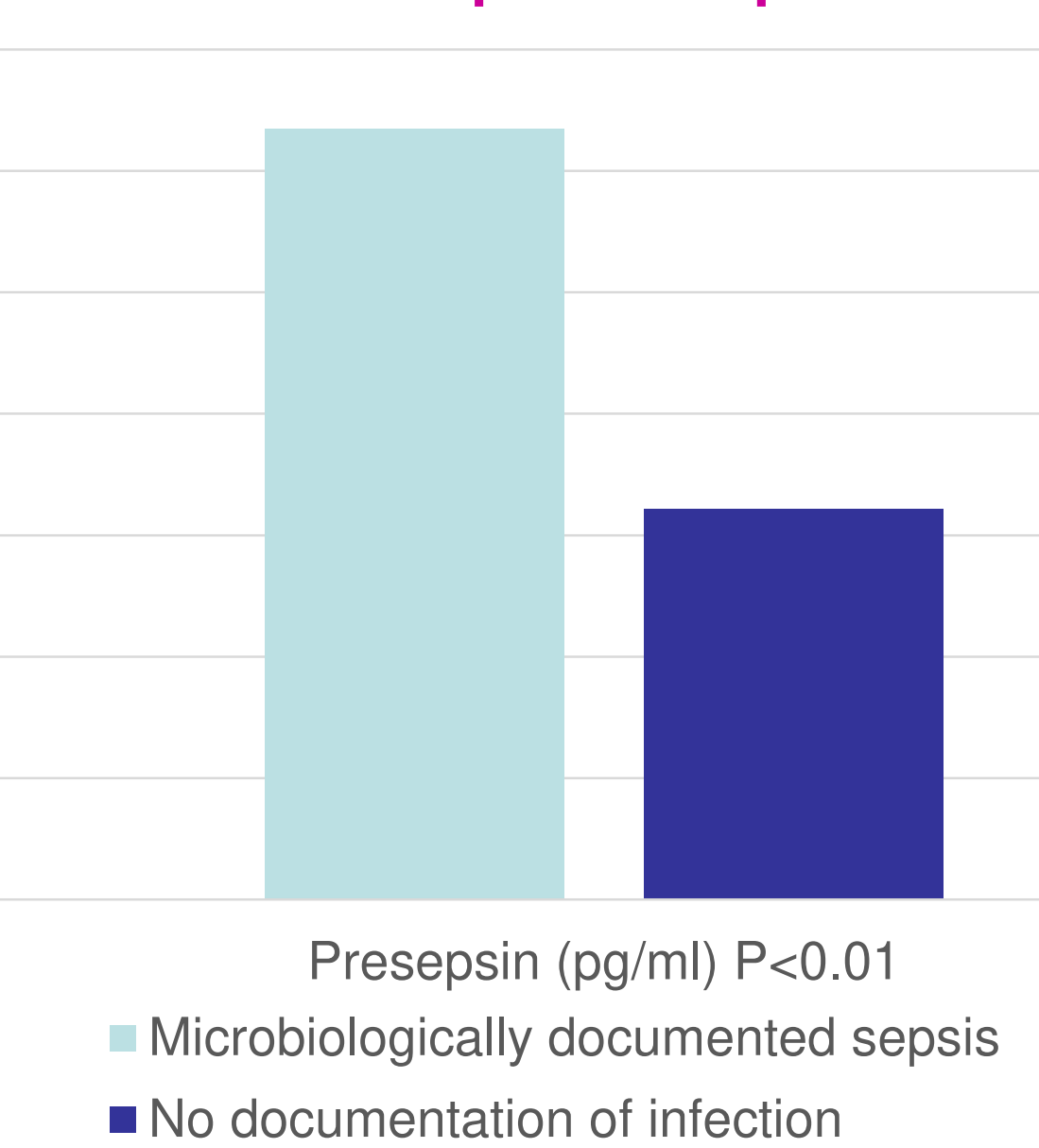

Background and Goal of Study: The criteria for sepsis recognition include the presence of systemic inflammatory response (SIRS) caused by infection which can be documented or highly suspected when the treatment of the patient is being initiated. However, it is very difficult to differentiate non-infectious SIRS from sepsis in many critically ill patients in order to timely begin proper anti-infection treatment. Pathogen identification from cultures and antimicrobial susceptibility testing take time, and there is a need for identification of biomarker that could early differentiate sepsis from non-infectious SIRS

The aim of our study was to determine whether levels of biomarkers that are mostly used for assessment of sepsis, measured within first 24 hours of SIRS development, could be used to determine the presence of microbiologically documented infection.

Methods: 100 patients with suspected sepsis were included in our study. To evaluate the diagnostic utility of the biomarkers, patients were classified into two groups: patients with microbiologically documented sepsis by positive cultures (blood cultures, urine, cerebrospinal fluid, wounds, respiratory secretions, or other body fluids that may be the source of infection) and patients with SIRS and suspected infection without microbiologically positive findings.

Procalcitonin (PCT), C-reactive protein (CRP), and presepsin levels, as well leucocyte count were determined within 24 when sepsis was suspected. Differences between groups of patients were assessed by Mann-Whitney U test. All P-values were two-sided and statistical significance was set at a value of 0.01 .
Concentration of PCT,CRP and leucocyte count in patients with suspected sepsis

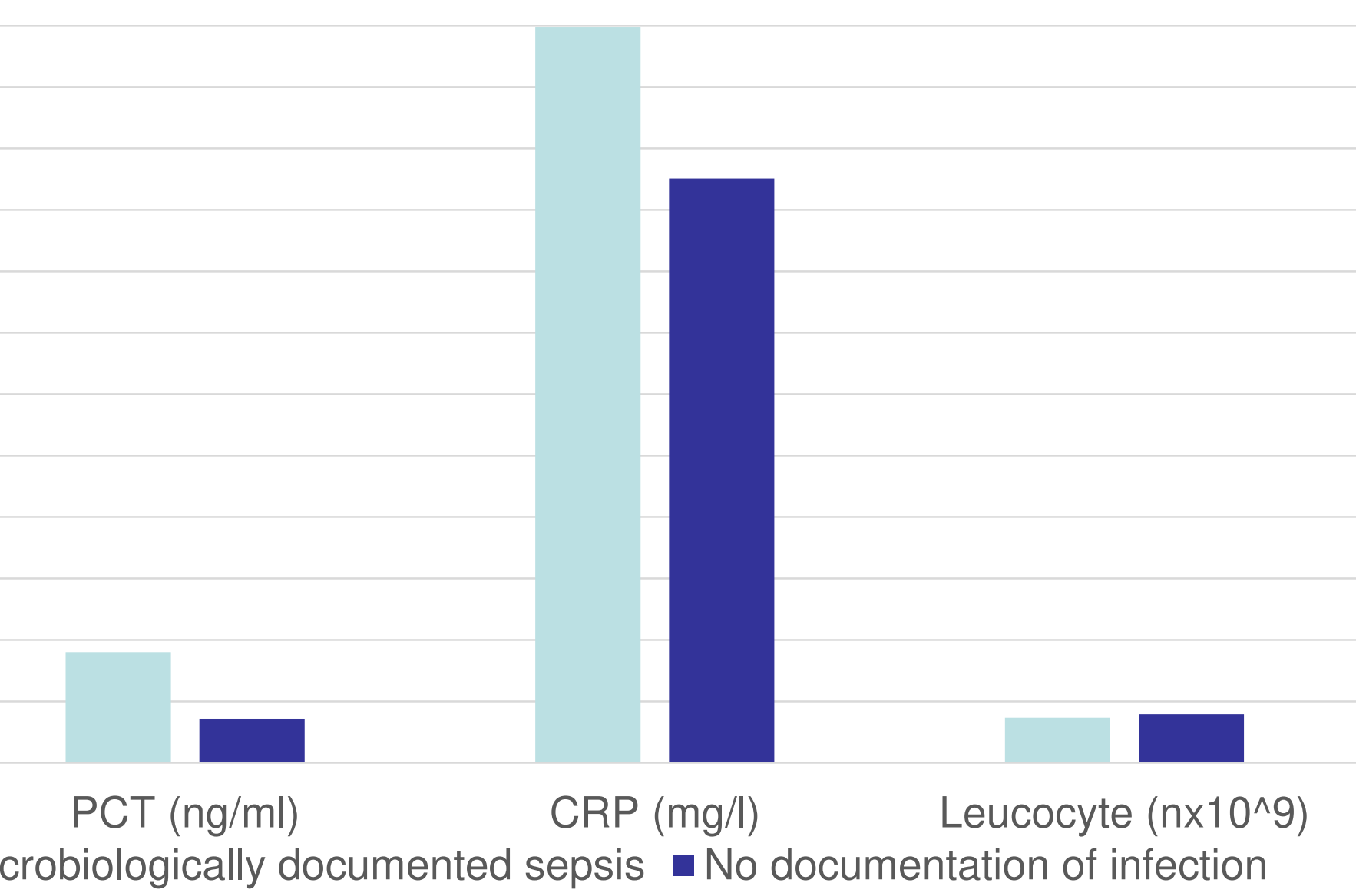

Results and discussion: Level of presepsin $(\mathrm{pg} / \mathrm{ml})$ were significantly higher in group of patients with documented infection in comparison to patients without documentation of infection (3173.33 \pm 4435.62 vs. 1607. $\pm 2087.94, p<0.01)$, while levels of PCT $(\mathrm{ng} / \mathrm{ml})$ (36.03 \pm 73.41 vs. $14.31 \pm 25.52, p=0.09)$, CRP (mg/l) $(239.6 \pm 382.35$ vs. $190.15 \pm 116.92, \mathrm{p}=0.75)$ and leucocyte count $(x 109 / /)(14.65 \pm 7.21$ vs. $15.77 \pm 9.08$, $\mathrm{p}=0.9)$ did not differ significantly.

\begin{tabular}{|l|l|l|l|}
\hline Variable & $\begin{array}{l}\text { Microbiologically } \\
\text { documented } \\
\text { sepsis }\end{array}$ & $\begin{array}{l}\text { No } \\
\text { documentation } \\
\text { of infection }\end{array}$ & $\mathbf{p}$ \\
\hline $\begin{array}{l}\text { Presepsin } \\
\text { (pg/ml) }\end{array}$ & $3173.33 \pm 4435.62$ & $1607 . \pm 2087.94$ & $<0.01$ \\
\hline PCT $(\mathrm{ng} / \mathrm{ml})$ & $36.03 \pm 73.41$ & $14.31 \pm 25.52$ & 0.09 \\
\hline CRP $(\mathrm{mg} / \mathrm{l})$ & $239.6 \pm 382.35$ & $190.15 \pm 116.92$ & 0.75 \\
\hline $\begin{array}{l}\text { Leucocyte } \\
\text { count } \\
\text { (nx10^9) }\end{array}$ & $14.65 \pm 7.21$ & $15.77 \pm 9.08$ & 0.9 \\
\hline
\end{tabular}

Data are expressed as mean $\pm S D$

Conclusion: Our results suggest that presepsin may be a helpful biomarker for identification of patients with infectious SIRS, documented by positive microbiological findings from cultures, with higher levels of this biomarker in patients with microbiologically documented sepsis.

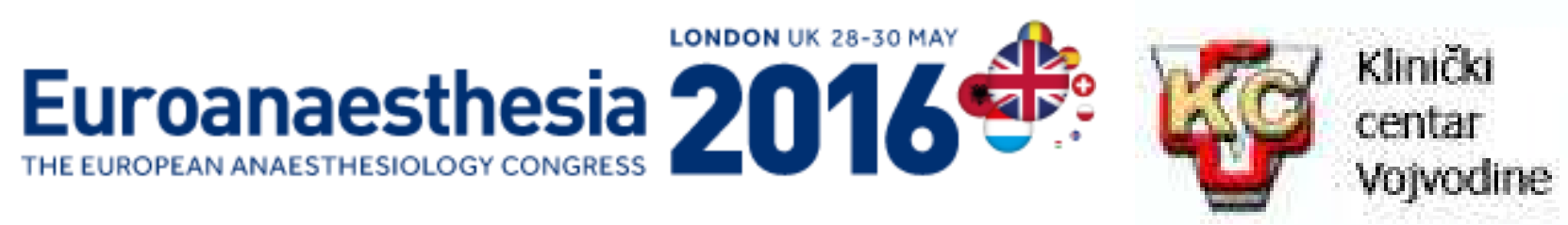

